\title{
Discourse Approach to Teaching Language and Communication Skills
}

\author{
Gohar Hovsepyan \\ Yerevan State University
}

\begin{abstract}
number of scholars have emphasized the importance of using findings of studies on the performance of speech acts in real-life conversations for teaching languages and communicative competence. Acts of communication such as giving advice or directives involve much more than the performance of a single speech act. The relevance of basing functional language teaching on the findings of discourse analyses has been attested by a number of publications (Cook 1989; McCarthy 1998; McCarthy and Carter 1994). McCarthy and Carter (1995) argue for a discourse approach to teaching grammar, and Dornyei and Thurrell (1994) believe a systematic approach to teaching conversational skills based on knowledge of how conversations are structured can take learners a long way towards second language acquisition. Other studies compare naturally occurring discourse with the language taught in textbooks. For example, Pearson (1986) examines agreeing and disagreeing, while Scotton and Bernsten (1988) analyze the language of direction-giving. Both authors draw attention to a discrepancy between the language of real-life discourse and the language of textbooks. Previous studies have therefore shown that a great deal can be learned from naturally occurring discourse for different areas of language teaching, ranging from grammar and vocabulary to pragmatic and sociolinguistic competence.

Pragmatic or functional uses of language, such as thanking, making suggestions, refusing, agreeing, asking for information, are important in many different types of interactions. Performing speech acts is a fairly complex phenomenon, which involves sociocultural knowledge about when to perform a speech act and which one to choose as appropriate in a given circumstance. The sociolinguistic knowledge regarding the actual linguistic realization of each speech act appropriate to the particular situation (Cohen 1996) is also an important component of the speech act. However, this complexity has not always been recognized in the teaching of speech acts or functions. There has frequently been an overly simplistic tendency to equate speech acts with certain linguistic formulae (McCarthy 1998:19), for instance to teach learners how to give advice, they may receive a list of phrases such as:
\end{abstract}

$$
\begin{aligned}
& \text { You should. . . } \\
& \text { Why don't you. . .? } \\
& \text { If I were you I'd. . . } \\
& \text { You ought to. . . }
\end{aligned}
$$

Such lists tend to obscure the fact that not all these phrases may be appropriate in every situation, depending on such factors as the precise nature of the interaction and the relationship between the speakers (e.g. status and social distance). A further com- 
plication may arise if there are sociocultural differences between the culture of the target language and the learner's culture regarding the type of speech act. Cohen (1996) remarks that in one culture a speech act such as thanking might be appropriate at the end of a meal, whereas in another culture the same situation would call for an apology.

Hymes argues that the study of language must concern itself with describing and analyzing the ability of the native speakers to use language for communication in real situations (communicative competence) rather than limiting itself to describing the potential ability of the ideal speaker to produce grammatically correct sentences (linguistic competence). Speakers of a language in particular communities are able to communicate with each other in a manner which is not only correct but also appropriate to the sociocultural context (Hymes 1989).

Another problem is that the teaching of speech acts has often focused on lists of phrases in isolation from any discourse context. Performing speech acts, however, usually involves more than such one-line contributions. As Cohen (1996) points out, several stages or "semantic formulas", as he calls them, are often involved, for example, for the act of apologizing: acknowledging responsibility, offering repair, giving an explanation or excuse. In addition, study of real-life conversations shows that performing speech acts is an intrinsically interactive phenomenon. After all, "doing" things like giving advice or making a request usually involves at least some kind of response from an addressee (advice may be either accepted or rejected), and usually a longer exchange. Conversation analysts have identified such minimal exchanges, or "adjacency pairs" (such as inviteaccept/refuse), as the basic unit of interaction in talk (Levinson 1983: 284-370). Research in conversation analysis has also demonstrated that the function of any utterance is dependent on its sequential placement in talk-in-interaction. Sacks (1987) and Schegloff $(1984,1988)$ show how the analysis of a speech act in isolation can lead to a completely different interpretation than that demonstrably arrived at by the participants in a conversation.

Hence, speech acts should be seen not as isolated phenomena, but as unfolding in discourse. Studying naturally occurring conversation can reveal how such acts or communicative functions are performed within longer stretches of discourse.

Insights gathered from the analysis of speech acts performed in naturally occurring spoken discourse have important implications for the teaching of functional language. For instance, various studies have indicated, that the performance of direct speech acts by means of performatives seems to be relatively unusual, with their use often limited to very specific communicative contexts and functions: for clarification, as framing devices to signal discourse goals, and as argumentative devices (Koester 2000). Clearly it is important for learners to be aware of these restrictions on the use of performatives: their incorrect use can have the unintended effect of the speaker sounding too direct or even rude. For example, Thomas (1984) shows that the inappropriate use of performatives can result in cross-cultural "pragmatic failure". Hence, it is important for learners to be able to correctly understand and use direct speech acts, and not take them at face value, without looking at the whole stretch of discourse. Performing communicative acts, such as 
giving advice or instructions, is an interactive endeavor, and different speech acts generate different discourse patterns and linguistic choices.

The above approach proceeds with the assumption that it is possible to teach pragmatic competence, however, mere exposure to language in natural contexts is not enough. This assumption is supported by a number of studies cited in Cohen (1996), showing that formal instruction can improve the ability to perform speech acts. In teaching speech acts, it is important to take into account both micro and macro levels of discourse. At the micro-level, learners need to learn appropriate responses for different types of initiating utterances. To a large extent, this is already part of current teaching practice, for example through "mini-dialogue" practice. What the analysis of naturally occurring conversation can contribute is a more accurate picture of the types of appropriate responses depending on the speech act, such as advice, instructions, offers. For instance, evaluation is usually a component of advice responses (e.g. that's a good idea), but not of responses to directives.

At the macro discourse level, learners need an opportunity to practice the discourse patterns of different types of conversations, including how to open and close conversations. One important aspect of pragmatic competence in this connection is the ability to make discourse frames explicit: to signal (e.g. through meta-statements such as This is only a suggestion, I was kidding, This is a request) what type of discourse one wishes to engage in.

Taking a discourse approach to teaching functions means that the speech acts to be taught should be generated from discourse types (e.g. making arrangements, giving instructions, service encounters), rather than occurring as separate elements in the syllabus (Burns and Joyce 1997; McCarthy and Carter 1994). The discourse or text types to be included in the syllabus depend of course on the aims of the course: a conversation course will require different discourse types than a course in legal English. One attempt to incorporate a discourse element into the syllabus is described in the learning objectives for the recently revised European Language Certificates (Teichmann and Kiefer 1998). One of the specified learning objectives is the ability to engage in the production of certain discourse types, called "scenarios", such as favor-seeking, narrating, etc. These scenarios integrate discourse structure with functions, strategies and lexical and grammatical features of a particular communicative setting.

There are various other options to use the insights gained from naturally occurring talk in instruction. Recordings and transcripts of actual conversations can be used for listening practice. Instructors can use the data to devise various other classroom tasks promoting communication skills. One well-known communicative activity which can be used to sensitize learners to the fact that conversations have structures and phases is an unjumbling task, where learners rearrange the parts of a conversation into the right order (either the transcript of a real-life conversation or a dialogue modelled on such a conversation can be used). In order to develop learners' productive ability in this area, role play activities can be devised: for example, learners can develop conversations from skeletons based on the different phases of the discourse. 
Sometimes minor adjustments to current teaching practice may be necessary. For example, learning how to paraphrase and check information is a skill which is commonly taught. What may be a new insight from discourse analysis is, for example, the importance of checking and clarifying through using "formulas" with performatives. One of the restricted uses of performatives aims at checking and clarifying (e.g. what I mean is. .., so you're saying. . .). Learners could be taught the use of such devices specifically for the skill of paraphrasing and checking understanding; and this skill can be practiced as a component of instructional discourse.

In teaching communicative functions, it is important to move away from simply teaching lists of phrases. In addition to being able to cope with the discourse dimension of speech acts, learners need to develop awareness of the differences between various realizations of the same speech act; for example, between explicit performatives and more indirect ways of communicating the same meaning. This means that language awareness activities should play an important role, which could involve, for instance, exposing learners to real-life recordings.

Teaching speech acts can also provide a rich opportunity for exploring sociolinguistic and cross-cultural issues. The appropriate realization and level of directness of any speech act is highly sensitive to the sociocultural context. This is particularly important when there is a status or power differential, as in the office environment. Again, familiar classroom tasks could be used to develop awareness of such sociocultural issues; for example identifying appropriate speech act realizations depending on speaker relationship (employer-employee or vice versa), i.e. through multiple choice, matching or more creative activities. Cross-cultural differences can also be explored, for example by comparing speech acts in the target language with the learners' language/culture and examining such questions as: which speech acts are appropriate to a particular situation; how these speech acts are realized; in which language or culture they are more direct, etc.

To sum up, discourse analysis can provide valuable insights into the way people interact through speaking, and thus its findings can be effectively used in sociolinguistics, cross-cultural communication and different areas of language teaching, including grammar, vocabulary, communication strategies, etc.

\section{References:}

1. Burns, A.; Joyce, H. (1997) Focus on Speaking. Sydney: Macquarie University.

2. Carter, R.A. (1998) Orders of Reality. // CANCODE, Communication, and Culture. ELT Journal, 52 (1). Oxford: OUP.

3. Cohen, A.D. (1996) Developing the Ability to Perform Speech Acts. // Studies in Second Language Acquisition, 18 (2). Cambridge: CUP.

4. Cook, G. (1989) Discourse. Oxford: OUP.

5. Dornyei, Z.; Thurrell, S. (1994) Teaching Conversational Skills Intensively: Course Content and Rationale. // ELT Journal, 48 (1). Oxford: OUP. 
6. Hymes, D.H. (Ed.) (1964) Language in Culture and Society: A Reader in Linguistics and Anthropology. New York: Harper \& Row.

7. Hymes, D.H. (1989) Ways of Speaking. // Explorations in the Ethnography of Speaking. / Ed. by R. Bauman and J. Sherzer. Cambridge: CUP.

8. Koester, A. (2000) Getting Things Done and Getting along in the Office. // Dialogue Analysis VII: Working with Dialogue: Selected papers from the 7th IADA Conference. / Ed. by M. Coulthard, J. Cotterill, F. Rock. Tubingen: Max Niemeyer Verlag GmbH.

9. Levinson, S.C. (1983) Pragmatics. Cambridge: CUP.

10. McCarthy, M.J. (1998) Spoken Language and Applied Linguistics. Cambridge: CUP.

11. McCarthy, M.J.; Carter, R.A. (1994) Language as Discourse: Perspectives for Language Teaching. London: Longman.

12. McCarthy, M.J.; Carter, R.A. (1995) Spoken Grammar: What Is It and How Can We Teach It? // ELT Journal, 49 (3). Oxford: OUP.

13. Pearson, E. (1986) Agreement/Disagreement: an Example of Results of Discourse Analysis Applied to the Oral English Classroom. // International Review of Applied Linguistics 74: De Gruyter Mouton.

14. Sacks, H. (1987) On the Preferences for Agreement and Contiguity in Sequences in Conversation. // Talk and Social Organization. / Ed. by G. Button \& J.R. Lee. Clevedon, UK: Multilingual Matters.

15. Schegloff, E. (1984) On Some Questions and Ambiguities in Conversation. // Structures of Social Action: Studies in Conversation Analysis. / Ed. by Atkinson, J. Heritage. Cambridge: CUP. J.M

16. Schegloff, E. (1988) Presequences and Indirection: Applying Speech Act Theory to Ordinary Conversation. // Journal of Pragmatics, 12. Elsevier.

17. Scotton, C.M. Bernsten, J. (1988) Natural Conversations as a Model for Textbook Dialogue. // Applied Linguistics 9 (4). Oxford: OUP.

18. Teichmann, H.D.; Kiefer, P. (1998) The European Language Certificates: Certificate in English. Learning Objectives and Test Format. Frankfurt am Main: WBT Weiterbildungs-Testsysteme $\mathrm{GmbH}$.

19. Thomas, J. (1984) Cross-cultural Discourse as "Unequal Encounter": Towards a Pragmatic Analysis. // Applied Linguistics, 5 (3). Oxford: OUP.

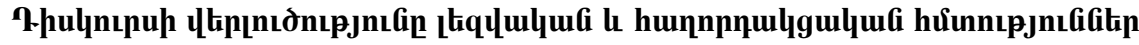 nıunıgufit_nı Gưuenulyn!}

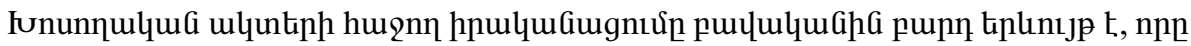

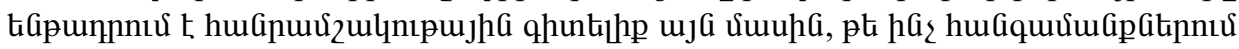

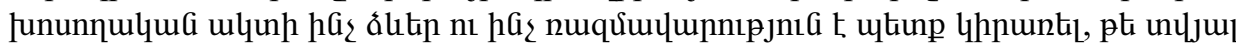

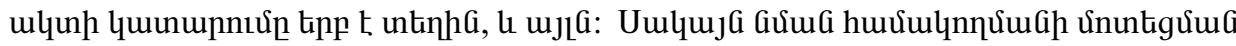

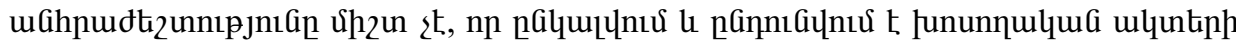

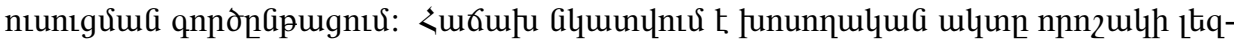

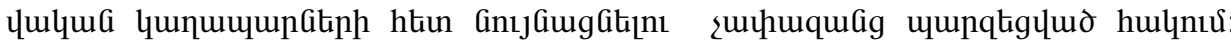




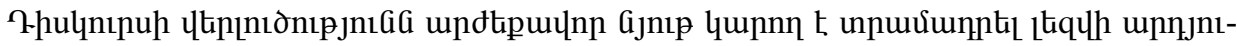

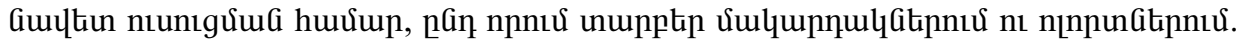

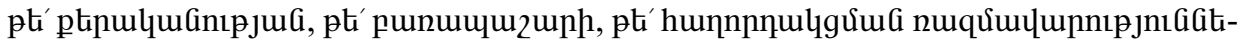

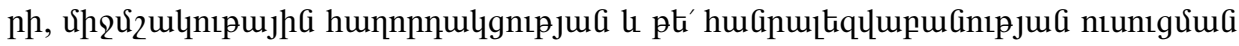
nuunGipuggitipnus: 